\section{Dermatology Reports: A journal coming to a new life}

Dermatology Reports is an open access journal published online since 2009. It is devoted to any aspects of dermatology and it is indexed in most citation databases, such as Medline and Embase.

Recently, the journal changed, in a sense, its life by becoming the Official Journal of the Italian Association of Hospital Dermatologists (ADOI Associazione Dermatologi-Venereologi Ospedalieri Italiani e della sanità pubblica) and, thanks to an agreement with ADOI, of the Italian Melanoma Intergroup (IMI).

Being the official journal of a national professional association poses new responsibilities to the journal editors, and traces some new ways for the journal, especially when one considers the already large number of scientific publications available to dermatologists.

The key word we, as editors, want to emphasise is Education. Educating professionals is our scope (Table). We will emphasise the role of research methodology and evidence based approaches in informing clinical practice. We will also exploit the value of single or multiple case reports to improve professional skills. A voice will be given to dermatological nurses who may find, in the journal, a sort of bridge to their medical counterpart, so that a better harmonization of activities can be promoted. We will also aim to have patient associations on board. The point of view of patients is vitally important. The structure of the papers in this case may not follow the usual format, a more unformal and narrative structure will be welcome.

Even if the journal will have, by its nature, an Italian perspective on the organization of clinical practice, it is very open to contributions from dermatologists of any country in the world with a global perspective.

We do not care that much about citation indexes or impact factor as usually measured in bibliometric analyses, but will care a lot about the satisfaction of contributors and of our readership. Please, feel free to comment on the contents of the journal and criticise us if you are not satisfied with the quality of the journal. We very much look forward to working with all of you to make the journal an ongoing enterprise to improve dermatological practice. Thank you in advance for the help you will provide us on such an ambitious task.

The Dermatology Reports Editors Luigi Naldi, Cesare Massone, Francesca Sampogna

The Italian Association of Hospital Dermatologists (ADOI) President Francesco Cusano
Correspondence: Luigi Naldi, Centro Studi GISED, Bergamo, 24100 (BG), Italy

E-mail: luigi.naldi@gised.it

Received for publication: 12 November 2020 . Accepted for publication: 12 November 2020.

This work is licensed under a Creative Commons Attribution-NonCommercial 4.0 International License (CC BY-NC 4.0).

OCopyright: the Author(s), 2020

Licensee PAGEPress, Italy

Dermatology Reports 2020; 12:9015

Table. Thematic areas of the journal.

Case Reports

Clinical Reviews

Imaging in Dermatology

Dermatopathology

Epidemiology/Public Health

Clinical Research

Melanoma and Dermato-oncology

Dermatosurgery

Procedural Dermatology

Psychodermatology

Sexually Transmitted Disease

Patient corner

Nursing

Medical humanities 